\title{
Contrasting patterns in the invasions of European terrestrial and freshwater habitats by alien plants, insects and vertebrates
}

Petr Pyšek ${ }^{1,2 *}$, Sven Bacher ${ }^{3}$, Milan Chytrý ${ }^{4}$, Vojtěch Jarošík ${ }^{1,2}$, Jan Wild ${ }^{1}$, Laura Celesti-Grapow ${ }^{5}$, Núria Gassó ${ }^{6}$, Marc Kenis ${ }^{7}$, Philip W. Lambdon ${ }^{8}$, Wolfgang Nentwig 9 , Jan Pergl ${ }^{1}$, Alain Roques ${ }^{10}$, Jiří Sádlo ${ }^{1}$, Wojciech Solarz ${ }^{11}$, Montserrat Vilà ${ }^{12}$ and Philip E. Hulme ${ }^{13}$

${ }^{1}$ Institute of Botany, Academy of Sciences of the Czech Republic, CZ-252 43 Prühonice, Czech Republic, ${ }^{2}$ Department of Ecology, Charles University Prague, Viničná 7, CZ-128 01 Prague, Czech Republic, ${ }^{3}$ Ecology and Evolution Unit, Department of Biology, University of Fribourg, Chemin du Musée 10, CH-1700 Fribourg, Switzerland, ${ }^{4}$ Department of Botany and Zoology, Masaryk University, Kotlářská 2, CZ-611 37 Brno, Czech Republic, ${ }^{5}$ Department of Plant Biology, La Sapienza University, Piazzale Aldo Moro 5, I-00185 Rome, Italy, ${ }^{6}$ Centre de Recerca Ecològica $i$ Aplicacions Forestals (CREAF), Universitat Autònoma de Barcelona, E-08193 Bellaterra, Spain, ${ }^{7} \mathrm{CABI}$ Europe-Switzerland, 1 Rue des Grillons, CH-2800 Delémont, Switzerland, ${ }^{8}$ Global Programmes Department, Royal Society for the Protection of Birds, The Lodge, Sandy, Bedfordshire SG19 2DL, UK, ${ }^{9}$ Institute of Ecology and Evolution, University of Bern, Baltzerstrasse 6, CH-3012 Bern, Switzerland,

${ }^{10}$ National Institute of Agronomical Research, INRA UR633, Zoologie Forestière, 2163 Av. Pomme de Pin, 45075 Orléans, France, ${ }^{11}$ Institute of Nature Conservation, Polish Academy of Sciences, Al. Mickiewicza 33, PL-31-120 Krakow, Poland, ${ }^{12}$ Estación Biológica de Doñana (EBD-CSIC), Avda. Américo Vespucio s/n, Isla de la Cartuja, E-41092 Sevilla, Spain, ${ }^{13}$ The Bio-Protection Research Centre, PO Box 84, Lincoln University, Canterbury, New Zealand

${ }^{\star}$ Correspondence: Petr Pyšek, Institute of Botany, Academy of Sciences of the Czech Republic, CZ-252 43 Průhonice, Czech Republic.

E-mail: pysek@ibot.cas.cz

\section{ABSTRACT}

Aim To provide the first comparative overview on the current numbers of alien species that invade representative European terrestrial and freshwater habitats for a range of taxonomic groups.

Location Europe.

Methods Numbers of naturalized alien species of plants, insects, herptiles, birds and mammals occurring in 10 habitats defined according to the European Nature Information System (EUNIS) were obtained from 115 regional data sets. Only species introduced after AD 1500 were considered. Data were analysed by ANCOVA and regression trees to assess whether differences exist among taxonomic groups in terms of their habitat affinity, and whether the pattern of occurrence of alien species in European habitats interacts with macroecological factors such as insularity, latitude or area.

Results The highest numbers of alien plant and insect species were found in human-made, urban or cultivated habitats; if controlled for habitat area in the region, wetland and riparian habitats appeared to support relatively high numbers of alien plant species too. Invasions by vertebrates were more evenly distributed among habitats, with aquatic and riparian, woodland and cultivated land most invaded. Mires, bogs and fens, grassland, heathland and scrub were generally less invaded. Habitat and taxonomic group explained most variation in the proportions of alien species occurring in individual habitats related to the total number of alien species in a region, and the basic pattern determined by these factors was fine-tuned by geographical variables, namely by the mainland-island contrast and latitude, and differed among taxonomic groups.

Main conclusions There are two ecologically distinct groups of alien species (plants and insects versus vertebrates) with strikingly different habitat affinities. Invasions by these two contrasting groups are complementary in terms of habitat use, which makes an overall assessment of habitat invasions in Europe possible. Since numbers of naturalized species in habitats are correlated among taxa within these two groups, the data collected for one group of vertebrates, for example, could be used to estimate the habitat-specific numbers of alien species for other vertebrate groups with reasonable precision, and the same holds true for insects and plants.

\section{Keywords}

Aquatic, continental scale, Europe, exotic, habitat affinities, invasive species, level of invasion, naturalized, non-native, weeds. 


\section{INTRODUCTION}

The role of habitats in determining the characteristics of biological invasions has been firmly established (Ruiz et al., 1997; Davis et al., 2000; Inderjit, 2005; Richardson \& Pyšek, 2006) and in general, individual habitats differ in the number of alien species they contain (e.g. Crawley, 1987; Alvarez \& Cushman, 2002; Byers, 2002; Radford et al., 2002; García-Robledo \& Murcia, 2005; Sádlo et al., 2007). However, surprisingly few studies provide quantitative data on the representation of alien species in particular habitats across regions, with the exception of alien floras (Chytrý et al., 2005, Pyšek et al., 2005; Maskell et al., 2006; Stohlgren et al., 2006; Vilà et al., 2007). Based on the differences in ecology and life histories among plants, insects and vertebrates, one may assume that these groups are likely to differ in habitat use, defined as the way an organism consumes resources (Hall et al., 1997). So, while there are general expectations regarding the vulnerability of a habitat to invasions by plants (Davis et al., 2000), a corresponding theory for animals is lacking and there are as yet no studies that have examined whether there are general principles applicable across a range of taxonomic groups.

The lack of a general assessment on the level of habitat invasion has up to now limited the possibilities of evaluating the invasion risks posed to different habitats, which is assumed to be a fundamental component of early detection and identification of those environments that are more prone to invasion, in order to optimize actions to prevent, monitor and control invasion (Zalba et al., 2000). In general, ability to evaluate invasion risks could be increased by developing composite indicators that track trends in a suite of invasive alien species with similar life histories, shared pathways and/or habitat associations (Hulme, 2006).

For that reason, the present study compared alien species distributions across ecosystems to assess the relative susceptibility of European habitats to invasion. The aims were to: (1) provide the first overview of the numbers of alien species in representative European terrestrial and freshwater habitats for a range of taxonomic groups; (2) assess whether differences exist among taxonomic groups in terms of the habitat affinity of their alien taxa; and (3) explore whether the pattern of occurrence of alien species in European habitats interacts with three macroecological factors known to influence species richness, such as insularity, latitude and area (Gaston \& Blackburn, 2000). These geographical factors have also been repeatedly shown to be important determinants of invasions at the continental and global scale (e.g. Lonsdale, 1999; Sax, 2001; Lambdon et al., 2008).

\section{METHODS}

\section{Habitat classification}

A standard classification of European habitats from the European Nature Information System (EUNIS; Davies et al., 2004, available at http://eunis.eea.europa.eu/habitats.jsp) was chosen as a convenient platform for evaluating biological invasions in Europe (Chytrý et al., 2008b). For the purposes of EUNIS, a 'habitat' is defined as 'a place where plants or animals normally live, characterized primarily by its physical features (topography, plant or animal physiognomy, soil characteristics, climate, water quality, etc.) and secondarily by the species of plants and animals that live there'. Most EUNIS habitats are in effect 'biotopes', i.e. 'areas with particular environmental conditions that are sufficiently uniform to support a characteristic assemblage of organisms' (Davies et al., 2004). We acknowledge that the EUNIS classes are broad definitions that do not necessarily meet the scientific definition of a habitat (e.g. Southwood, 1977; Thackway \& Lesslie, 2006) but rather represent habitat types (arbitrary sections of the habitat continuum); for ease of reading we refer to these classes as 'habitats'.

The hierarchical nature of the EUNIS system composed of several nested levels facilitated the assignment of species records to particular habitats across Europe. We combined Levels 1 and 2 of the EUNIS hierarchy to take into account specific features of invasions by plants and animals of various terrestrial and freshwater habitats. For example, it is plausible to consider inland surface waters and riparian habitats as separate categories, because they are known to differ in their level of invasion, environmental conditions and ecological dynamics (Hood \& Naiman, 2000; Richardson et al., 2007). The resulting classification included 10 habitat types: rocky and sandy coasts (hereafter termed coastal, EUNIS class B); inland surface waters, standing and running (aquatic, EUNIS classes C1 + C2); wetland and riparian habitats, consisting of a littoral zone of inland surface waterbodies and stream sides, sedge and reedbeds, and inland saline and brackish marshes (riparian, EUNIS classes C3 + D5 + D6); mires, bogs and fens (mires, EUNIS classes D1-D4); grasslands and lands dominated by forbs, mosses or lichens (grassland, EUNIS class E); heathland, scrub and tundra (heathland/scrub, EUNIS class F); woodland, forest and other wooded land (woodland, EUNIS class G); inland unvegetated or sparsely vegetated habitats (bare land, EUNIS class $\mathrm{H}$ ); regularly or recently cultivated agricultural, horticultural and domestic land (cultivated, EUNIS class I); and constructed, industrial and other artificial land, which includes human settlements, buildings, industrial developments, transport networks and waste dump sites (urban, EUNIS class J) (Appendix S1 in Supporting Information).

The areas of each habitat were obtained from CORINE land cover (Bossard et al., 2000, version 8/2005 obtained from the European Environment Agency), using a cross-walk between these spatial data and EUNIS habitat categories (Slootweg et al., 2005). Following this cross-walk, if a CORINE land-cover category could not be unequivocally assigned to a single EUNIS habitat, its area was estimated based on the proportions of corresponding EUNIS habitat types. Modifications of the Slootweg et al. (2005) cross-walk reflected the classification of EUNIS habitats used in our study: inland marshes (CORINE class 411) comprised $50 \%$ of C3 + D5 + D6 and 50\% of D1-4 EUNIS habitats; water courses (CORINE class 511) and waterbodies (CORINE class 512) each comprised $50 \%$ of $\mathrm{C} 1+\mathrm{C} 2$ and $50 \%$ 
of C3 + D5 + D6; and salt marshes, saline and intertidal habitats (CORINE classes 421-423) corresponded to EUNIS habitat B.

The area of aquatic habitats is underestimated in CORINE data due to their $250 \times 250 \mathrm{~m}$ resolution that fails to recognize small to medium streams and small waterbodies. This bias was corrected using independent and more detailed land-cover data of $25 \times 25 \mathrm{~m}$ resolution based on combined field and satellite data from two countries: the Czech Republic (GISAT 2004-08) and the United Kingdom (DEFRA 2000). The observed difference between CORINE and detailed surveys was consistent in both countries: compared with these sources, the area of surface waters in CORINE was underestimated by $32 \%$ and $36 \%$ in the Czech Republic and UK, respectively. The average value for both countries was used to correct the area of aquatic habitats.

\section{Data sources and variables}

In total, 114 regional data sets were collated (see Appendix S1 for the delimitation of regions) for the following taxonomic groups: vascular plants 15 (3 mainland/12 island), insects $15(12 / 3)$, herptiles 22 (16/6), birds 6 (5/1) and mammals 56 (39/17). For each region and taxonomic group, lists of naturalized (established) alien species sensu Richardson et al. (2000) and Pyšek et al. (2004b, 2009) were collated using data sources outlined in Appendix S1. Only species introduced after the year 1500 were considered, and alien status was evaluated on a regional rather than continental basis, i.e. species native to other parts of Europe but introduced to the respective region were considered as aliens in that region. In this paper, the term 'alien' is used for naturalized alien species.

Species were assigned to particular habitats following the modified EUNIS classification outlined above and based on the literature, database sources and unpublished data. The information for most taxonomic groups was primarily based on the literature but an unpublished database was a major source of information for insects (Appendix S1). Species that occurred in more than one habitat were assigned to each of them, but not if this occurrence was rare or sporadic. Given the coarse classification of habitats, the most heterogeneous category of the urban habitats $(\mathrm{J})$ consists of a mosaic of various microhabitats which lead to the occurrence of species with various habitat affinities. In vertebrates, species that primarily live and feed in or on water were assigned to aquatic habitats $(\mathrm{C} 1+\mathrm{C} 2)$, while those that are only partially associated with aquatic habitats were assigned to riparian habitats (C3 + D5 + D6). Similarly, insects with larvae developing in water and adults living in terrestrial habitats were assigned to aquatic habitats $(\mathrm{C} 1+\mathrm{C} 2)$ except for a few alien mosquitoes which were also assigned to urban habitats $(\mathrm{J})$ since they frequently develop in human-made waterbodies such as used tyres.

This yielded, for each region and taxonomic group, the numbers of alien species associated with each habitat, which is a measure of the maximum level of invasion (sensu Hierro et al., 2005; Richardson \& Pyšek, 2006) likely to be currently experienced by a habitat at a regional scale. To obtain a relative measure, this number was expressed as a percentage of the total number of alien species occurring in the region. To analyse the main geographical factors that could determine the number of alien species in European habitats, regions were characterized by: (1) insularity (island or mainland), (2) mid latitude, and (3) total area.

\section{Statistical analysis}

Data were analysed by ANCOVA with the following response variables: (1) the number of alien species and (2) the proportion of the total number of alien species that occur in a particular habitat expressed as a percentage of all alien species recorded in the region. In the analysis of the number of alien species the explanatory variables were habitat area, habitat and taxonomic group, whereas for the proportion of the total number of species they were the taxonomic group, insularity, latitude and habitat. Where alien species were reported from a habitat, but CORINE data did not include that habitat for the given region because of its small area, habitat area was arbitrarily set to $1 \mathrm{~km}^{2}$. To normalize the data, numbers of alien species were square-rooted, proportions of total numbers of alien species angular transformed, and habitat areas $\ln$ transformed (e.g. Sokal \& Rohlf, 1995). To take into account that the total number of collated regional data sets differed for individual taxa, which may give an undue influence to small data sets (i.e. larger data are giving more precise estimates, especially for proportions; see, e.g., Crawley, 2002), the data for each taxon were weighted by the total number of data sets for each taxon in the overall sample of the 115 regional data sets. To avoid prediction of negative counts for a small habitat area, analysis of the number of alien species was completed by using a generalized linear model on counts with a log link function and Poisson distribution of errors, which were corrected for over-dispersion by dividing Pearson's chi-square by the residual degrees of freedom (McCullagh \& Nelder, 1989; Appendix S2).

The modelling of all ANCOVAs started with fitting a model that had all possible interactions among the explanatory variables. The parameters of this model were inspected, and the least significant term was removed in a deletion test, provided that its deletion caused a non-significant increase in deviance. Deletion tests were repeated until minimal adequate models (MAMs) were established. In MAMs, all non-significant parameters were removed, and all the remaining parameters were significantly $(P$ $<0.05$ ) different from zero and from one another (Crawley, 1993). The adequacy of the fitted models was checked by plotting standardized residuals against fitted values, and by normal probability plots. Their explained variance was expressed by $r^{2}$, which for the generalized linear model was approximated as $r_{\mathrm{L}}^{2}$ (Quinn \& Keough, 2002, pp. 370-2); where appropriate for comparison of different models, explained variance was expressed also as $r_{\text {adj }}^{2}$ which takes into account sample sizes and the number of predictors.

To provide understandable and generally interpretable descriptions of interactions between explanatory variables in ANCOVAs, regression trees (Breiman et al., 1984; De'ath \& Fabricius, 2000) were used to explore the effect of explanatory vari- 
ables on the proportions of the total number of alien species, separately for each taxonomic group. Regression trees are appropriate for these analyses, due to their flexibility and robustness, their invariance to monotonic transformations of predictor variables, their ability to use combinations of explanatory variables that are either categorical and/or numeric, their ability to deal with nonlinear relationships and high-order interactions, and, despite all these analytical difficulties, their ability to give easily understandable and interpretable results, providing an intuitive insight into the kinds of interactions between the explanatory variables (De'ath \& Fabricius, 2000). Trees thus also appeared suitable for exploring data of varying quality, with caveats resulting from a certain level of uncertainty in assigning species to habitats (see Chytrý et al., 2008a; Hejda et al., 2009). The trees, weighted as in the ANCOVAs by the number of available data sets for each taxon to avoid undue influence of small data sets, were constructed by repeatedly splitting the response variable using binary recursive partitioning in CART ${ }^{\circledR}$ version 6.0 (Breiman et al., 1984; Steinberg \& Colla, 1995), which uses the most reliable pruning strategy of overgrown trees, ensuring that any important tree structure is not overlooked. To find the best tree, a sequence of nested trees of decreasing size, each being the best of all trees of its size, was grown, and their resubstitution relative errors, corresponding to residual sums of squares, were estimated. Tenfold cross-validation was used to obtain estimates of relative errors of these trees. These estimates were then plotted against tree size, and the best tree was chosen both based on the minimum cost tree rule, which minimizes the crossvalidated error (the default setting in CART version 6.0; Steinberg \& Colla, 1995, p. 43), and based on the SE rule 1, which minimizes cross-validated error within one standard error of the minimum (Breiman et al., 1984). Following De'ath \& Fabricius (2000), a series of 50 cross-validations was run, based on each rule, and the modal (most likely) single tree chosen for description. To reduce the splitting power of categorical variables and to eliminate their inherent advantage over continuous variables, penalization rules, described by Steinberg \& Colla (1995), were followed. To check the appropriateness of the trees, residuals were plotted against predicted values of their terminal nodes (Quinn \& Keough, 2002). The quality of the best tree was described as the total explained variance, calculated as $r^{2}=1-$ resubstitution relative error, which is comparable with the explained variance in ANCOVAs (De'ath \& Fabricius, 2000). The quality of each split was expressed by its improvement value, corresponding to the proportion of the total sum of squares explained by the split.

The best trees were represented graphically, with the root standing for undivided data at the top, and the terminal nodes, describing the most homogeneous groups of data, at the bottom of the hierarchy. The initial best trees used the default minimal sample size of the terminal nodes $(n=1)$. However, for mammals this best tree produced 62 terminal nodes; to simplify interpretation, another best tree was selected, with its size constrained to have at least 30 records at each terminal node. However, this tree was still hard to interpret in a biological sense due to its large size. Consequently, improvement values were used to limit this best tree to a size corresponding to the number of splits which explained $95 \%$ of its total variance. This limitation was achieved by setting a complexity parameter, which stops the tree-growing process by placing a penalty on trees larger than the chosen value of the complexity parameter (Breiman et al., 1984; Steinberg \& Colla, 1995). The chosen limited best tree with the complexity parameter thus missed the lowest terminal nodes, which, however, contained only $5 \%$ of the total variance.

\section{RESULTS}

\section{Numbers and densities of alien plant and animal species in European habitats}

In terms of the numbers of alien species, plants and insects were more numerous than vertebrates (Appendix S1). On average per region there were $161 \pm 147$ (mean $\pm \mathrm{SD}, n=15$ ) plant and 202 \pm 148 insect species $(n=15)$ with attributed habitat affiliation, while the corresponding figures for herptiles, birds and mammals were only $6 \pm 4(n=56), 13 \pm 11(n=6)$ and $5 \pm 5$ $(n=22)$, respectively. The habitat affiliation was known for almost all vertebrate species (on average $99-100 \%$ in the three groups), $97 \%$ of insects and $75 \%$ of the plants.

Urban habitats harboured on average most alien plants and insects. Both plants and insects were also frequent on cultivated land. For insects, woodland was the only other habitat where many alien species were found, while the number of alien plants exceeded 20 in several other habitats (Fig. 1a). Species richness of vertebrates was more evenly distributed among habitats, with maxima in cultivated and aquatic habitats for birds. The numbers of alien mammals and herptiles on average did not exceed four; the former reached its maximum in woodland, the latter in cultivated habitats (Fig. 1b).

Alien species densities (Fig. 1c, d; Appendix S1) indicated a different pattern. Both plants and insects still reached their highest species densities in urban habitats, but if habitat area was taken into account, riparian habitats also exhibited high plant species densities (Fig. 1c). Riparian and aquatic habitats were also most heavily invaded by mammals and herptiles; the latter group also reached high species densities in mires. The highest densities of alien bird species were found in aquatic and cultivated habitats (Fig. 1d).

Alien species numbers in particular habitats were mutually correlated between the three vertebrate groups. The number of alien insect species was highly significantly correlated with that of plants (Table 1). There were no significant correlations between insects/plants and vertebrates.

\section{Relationship between alien species numbers and habitat area}

Across habitats, the increase in alien species numbers with increasing habitat area was slowest for the three vertebrate groups, herptiles, birds and mammals (line $y 4$ in Fig. 2), intermediate for plants (line $y 1$ ), and fastest for insects (line $y 2$ ). 
a

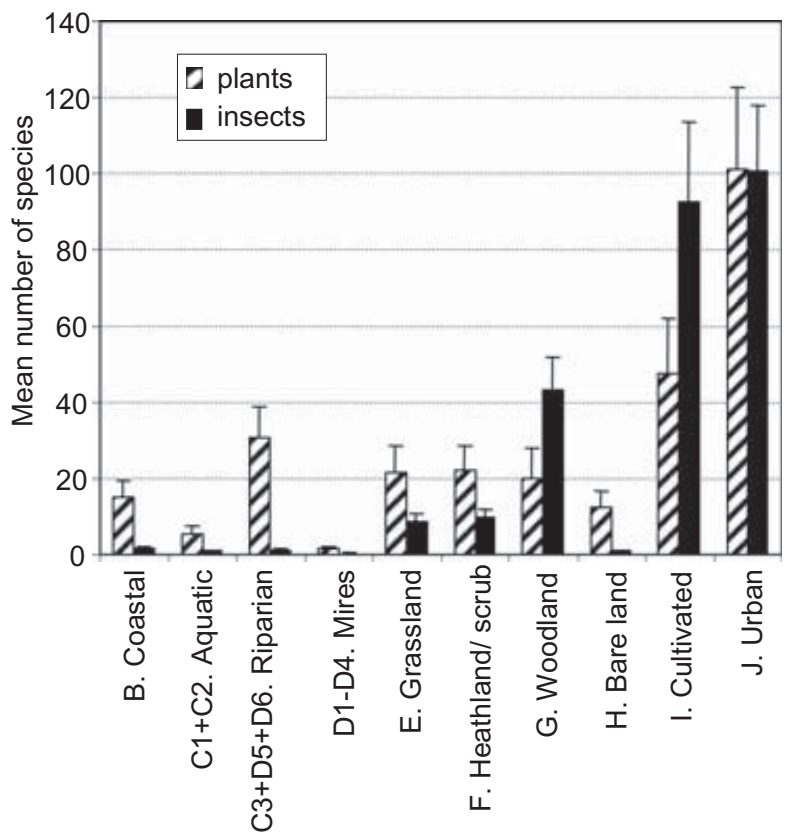

C

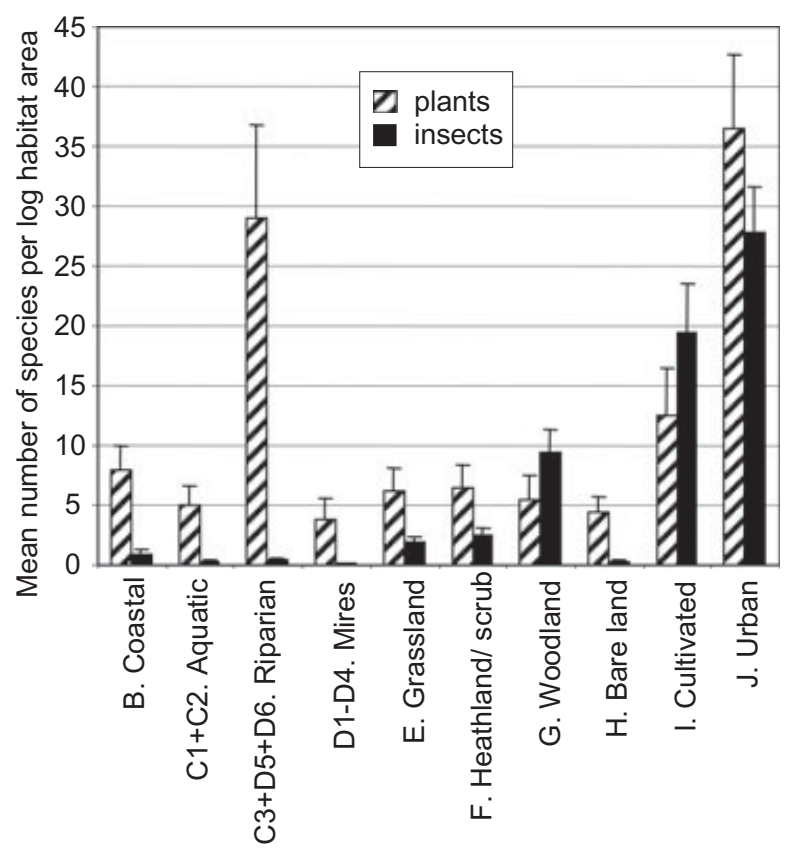

b
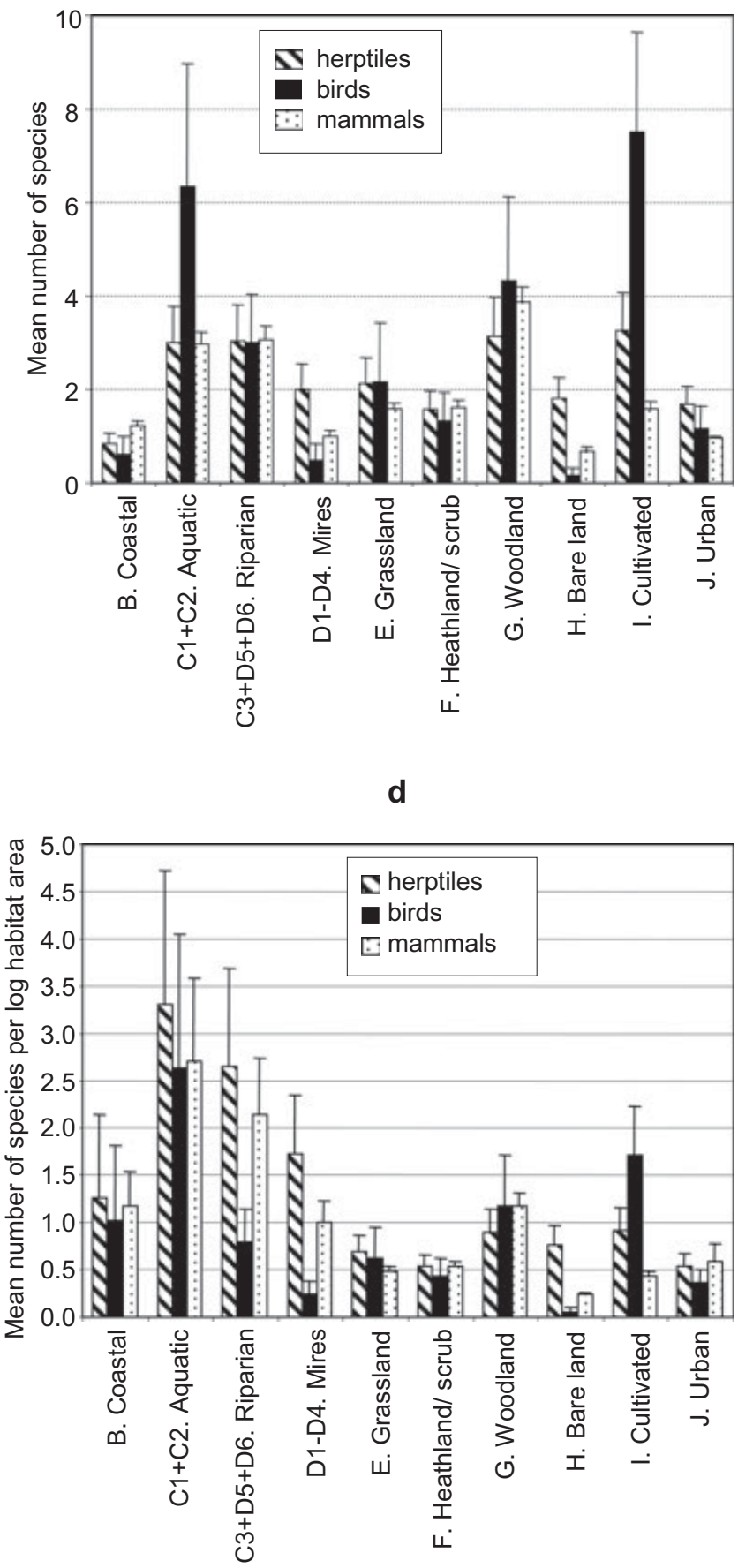

Figure 1 Mean numbers ( \pm SE) of alien species of plants and insects (a) and vertebrates (b) naturalized in European habitats, and naturalized species density, expressed as the mean number of species per log (habitat area in $\left.\mathrm{km}^{2}+1\right)(c, d)$. See Appendix S1 for data from individual regions and habitats and text for details on obtaining areas of habitats.

Across taxa, the rate of increase was the same in all habitats (deletion test on different rates of increase in individual habitats: $F_{9,859}=0.93$; not significant) but the habitats differed in the number of invading species (lines $y 3-y 5$ in Fig. 2). Overall, the species-area relationship explained $49.3 \%$ of the variance (Fig. 2).

\section{Proportions of the total number of alien species compared among habitats}

The proportions of the total number of alien species that occur in a particular habitat relative to the total number of all alien species in the region were summarized for each taxonomic 
group. There were two groups of taxa (plants and insects versus herptiles, birds and mammals) that showed very different distribution patterns of alien species across habitats. In general, plants and insects reached their highest values in urban and

Table 1 Correlation between the numbers of alien species and the taxonomic groups studied in European habitats $(n=10)$. Correlation coefficients and $P$-levels are shown; those significant at $P \leq 0.05$ are in bold.

\begin{tabular}{lllll}
\hline & Plants & Insects & Herptiles & Birds \\
\hline Insects & $\mathbf{0 . 8 6}$ & $\times$ & & \\
& $\boldsymbol{P}<\mathbf{0 . 0 1}$ & & & \\
Herptiles & -0.09 & 0.30 & $\times$ & \\
& $P=0.98$ & $P=0.41$ & & \\
Birds & 0.01 & 0.27 & $\mathbf{0 . 8 2}$ & $\times$ \\
& $P=0.99$ & $P=0.45$ & $\mathbf{P}<\mathbf{0 . 0 1}$ & \\
Mammals & -0.27 & -0.15 & $\mathbf{0 . 6 7}$ & $\mathbf{0 . 6 3}$ \\
& $P=0.46$ & $P=0.68$ & $\boldsymbol{P}<\mathbf{0 . 0 5}$ & $\boldsymbol{P}=\mathbf{0 . 0 5}$ \\
& & & &
\end{tabular}

cultivated habitats, while vertebrates reached their highest values in woodland, riparian, aquatic and cultivated habitats (Table 2).

The taxonomic group was therefore the most important single factor determining the proportions of total number of alien species in individual habitats. However, the taxonomic group significantly interacted with geographical factors, such as insularity and latitude, and there were also interactions of the habitat with other explanatory variables (Table 3, all taxa). When each taxon was analysed separately, habitat had an overwhelming effect, but there were still significant interactions with other explanatory variables within each taxonomic group (Table 3).

Regression trees (Fig. 3) indicated that the effect of habitat was statistically significant. Proportions of alien plant (Fig. 3a) and insect species (Fig. 3b) reached the highest values in urban habitats; for insects, cultivated habitats also had a comparably high value. Intermediate values were observed in woodland for insects, and cultivated, bare land and riparian habitats for

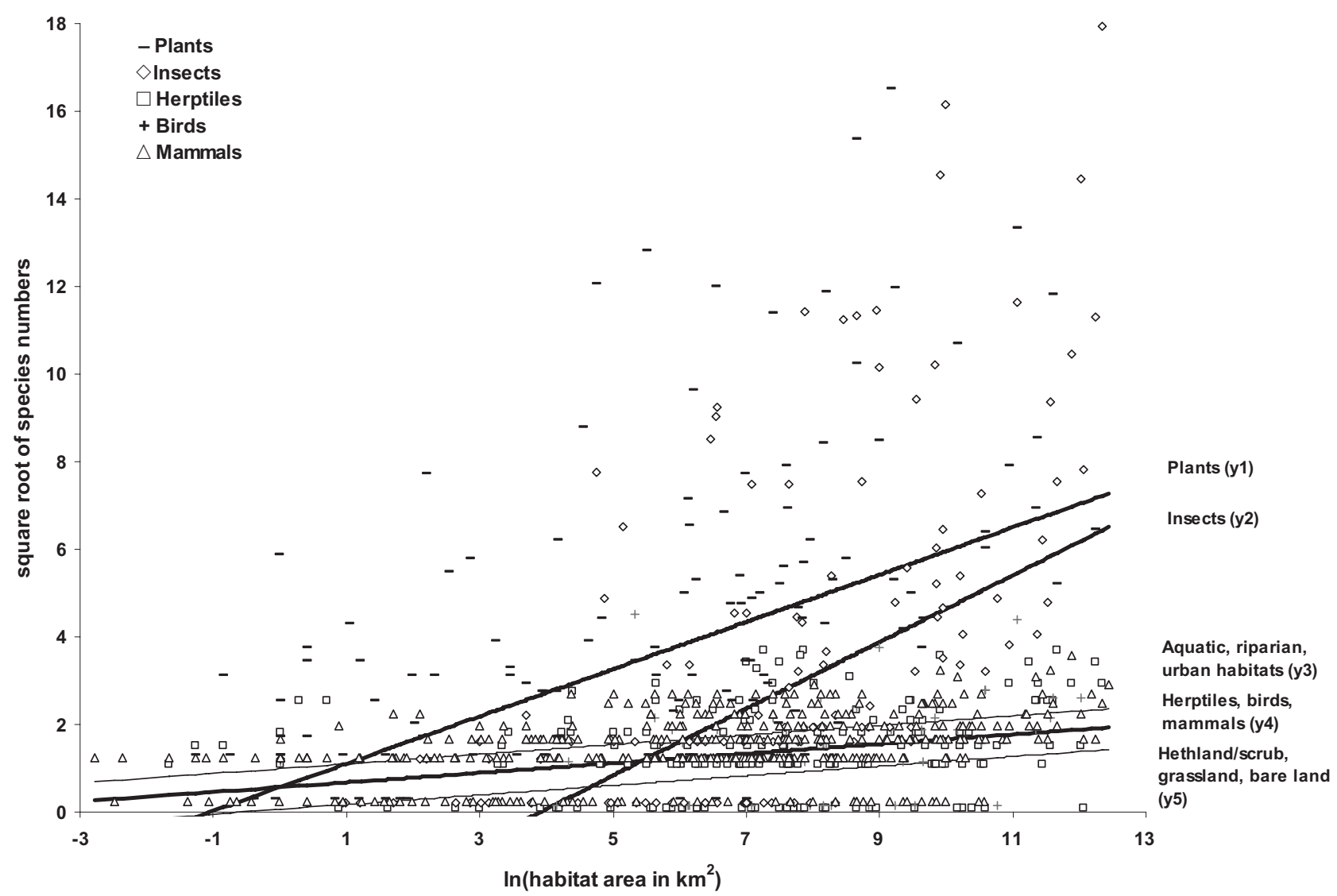

Figure 2 Relationship between alien species numbers ( $y$, square root transformed) and habitat area $(x$, ln transformed), analysed by ANCOVA. Plants: $y 1=0.57+0.54 x$; insects: $y 2=-2.97+0.76 x$; aquatic, riparian and urban habitats (only fitted data are shown for habitats, thin line): $y 3=0.99+0.11 x$; herptiles, birds, mammals + mires, coastal, woodland and arable land habitats (only fitted data are shown for habitats): $y 4=0.57+0.11 x$; heathlands/scrub, grassland and bare land habitats (only fitted data are shown for habitats, thin line): $y 5=0.06+0.11 x$. Statistics for the minimal adequate model are $F=142.7 ;$ d.f. $=6,880 ; P<0.001 ; r^{2}=0.493$. Some observed data on plants, insects, herptiles, birds and mammals are slightly shifted to make all points visible. See Appendix S2 for an alternative generalized linear model with log-link function and Poisson errors, which avoids the prediction of negative counts at small habitat area. 
Table 2 Invasions of European terrestrial and aquatic habitats by alien plants and animals. The measure used is percentage of the total number of naturalized alien species in a region that occur in particular habitat types. Means and ranges (in brackets) across the study regions are shown. See text for full habitat names and Table 3 and Fig. 3 for the statistical analysis of data.

\begin{tabular}{|c|c|c|c|c|c|}
\hline Habitat & Plants & Insects & Herptiles & Birds & Mammals \\
\hline Number of regions & 15 & 15 & 22 & 6 & 56 \\
\hline Coastal & $8(0-21)$ & $1(0-5)$ & $19(0-100)$ & $8(0-20)$ & $26(0-100)$ \\
\hline Aquatic & $2(0-8)$ & $0(0-1.2)$ & $55(0-100)$ & $51(11-83)$ & $55(0-100)$ \\
\hline Riparian & $25(4-50)$ & $1(0-2.4)$ & $60(0-100)$ & $41(0-83)$ & $56(0-100)$ \\
\hline Mires & $2(0-8)$ & $0(0-1)$ & $41(0-100)$ & $3(0-11)$ & $15(0-50)$ \\
\hline Grassland & $13(0-62)$ & $4(2-8)$ & $42(0-100)$ & $13(0-46)$ & $31(0-100)$ \\
\hline Heathland/scrub & $13(0-37)$ & $5(1-7)$ & $34(0-100)$ & $11(0-33)$ & $31(0-100)$ \\
\hline Woodland & $10(0-68)$ & $21(10-50)$ & $62(0-100)$ & $32(17-40)$ & $74(25-100)$ \\
\hline Bare land & $8(0-35)$ & $1(0-2)$ & $33(0-100)$ & $2(0-11)$ & $11(0-50)$ \\
\hline Cultivated & $34(5-95)$ & $43(26-66)$ & $63(0-100)$ & $65(51-80)$ & $30(0-100)$ \\
\hline Urban & $70(41-100)$ & $54(11-76)$ & $38(0-100)$ & $14(0-33)$ & $26(0-100)$ \\
\hline
\end{tabular}

Table 3 Minimal adequate models of ANCOVA describing the effect of invaded habitat type, taxonomic group, insularity and latitude in Europe on the proportions of the total number of naturalized alien species that occur in a particular habitat relative to the total number of naturalized alien species in the region. See Fig. 3 for detailed results based on regression trees.

\begin{tabular}{|c|c|c|c|c|c|c|}
\hline Taxon & $r_{\text {adj. }}^{2}$ & Source of variation & d.f. & MS & $F_{\mathrm{s}}$ & $P$ \\
\hline \multirow[t]{7}{*}{ All taxa } & 0.48 & Insularity & 1 & 1.10 & 0.29 & n.s. \\
\hline & & Taxon & 4 & 104.38 & 27.80 & $<0.001$ \\
\hline & & Insularity $\times$ habitat & 18 & 158.61 & 42.25 & $<0.001$ \\
\hline & & Taxon $\times$ latitude & 5 & 9.93 & 2.64 & $<0.05$ \\
\hline & & Taxon $\times$ habitat & 36 & 19.28 & 5.14 & $<0.001$ \\
\hline & & Habitat type $\times$ latitude & 9 & 9.11 & 2.43 & $<0.01$ \\
\hline & & Residuals & 1047 & 3.75 & & \\
\hline \multirow[t]{5}{*}{ Plants } & 0.67 & Insularity & 1 & 2.21 & 4.28 & $<0.05$ \\
\hline & & Latitude & 1 & 3.34 & 6.46 & $<0.05$ \\
\hline & & Habitat & 9 & 17.18 & 33.19 & $<0.001$ \\
\hline & & Insularity $\times$ latitude & 1 & 4.59 & 8.86 & $<0.01$ \\
\hline & & Residuals & 136 & 0.52 & & \\
\hline \multirow[t]{8}{*}{ Insects } & 0.97 & Insularity & 1 & 0.05 & 1.18 & n.s. \\
\hline & & Latitude & 1 & 0.05 & 1.08 & n.s. \\
\hline & & Habitat & 9 & 19.73 & 462.40 & $<0.001$ \\
\hline & & Insularity $\times$ latitude & 1 & 0.44 & 10.44 & $<0.01$ \\
\hline & & Insularity $\times$ habitat & 9 & 0.39 & 9.06 & $<0.001$ \\
\hline & & Latitude $\times$ habitat & 9 & 0.11 & 2.59 & $<0.01$ \\
\hline & & Insularity $\times$ latitude $\times$ habitat & 9 & 0.68 & 15.97 & $<0.001$ \\
\hline & & Residuals & 107 & 0.04 & & \\
\hline \multirow[t]{4}{*}{ Herptiles } & 0.14 & Latitude & 1 & 23.94 & 4.29 & $<0.05$ \\
\hline & & Habitat type & 9 & 19.21 & 3.44 & $<0.001$ \\
\hline & & Latitude $\times$ habitat & 9 & 11.87 & 2.13 & $<0.05$ \\
\hline & & Residuals & 196 & 5.58 & & \\
\hline \multirow[t]{2}{*}{ Birds $^{*}$} & 0.52 & Habitat & 9 & 3.31 & 8.04 & $<0.001$ \\
\hline & & Residuals & 49 & 0.41 & & \\
\hline \multirow[t]{5}{*}{ Mammals } & 0.53 & Insularity & 1 & 0.22 & 0.04 & n.s. \\
\hline & & Latitude & 1 & 21.02 & 4.27 & $<0.05$ \\
\hline & & Habitat & 9 & 212.87 & 43.21 & $<0.001$ \\
\hline & & Insularity $\times$ habitat & 9 & 132.64 & 26.93 & $<0.001$ \\
\hline & & Residuals & 529 & 4.93 & & \\
\hline
\end{tabular}

n.s., not significant; MS, mean square.

*Sample size too small to fit interactions between the explanatory variables.

$r_{\text {adj }}^{2}$ takes into account sample sizes and the number of predictors. 
(a) Plants

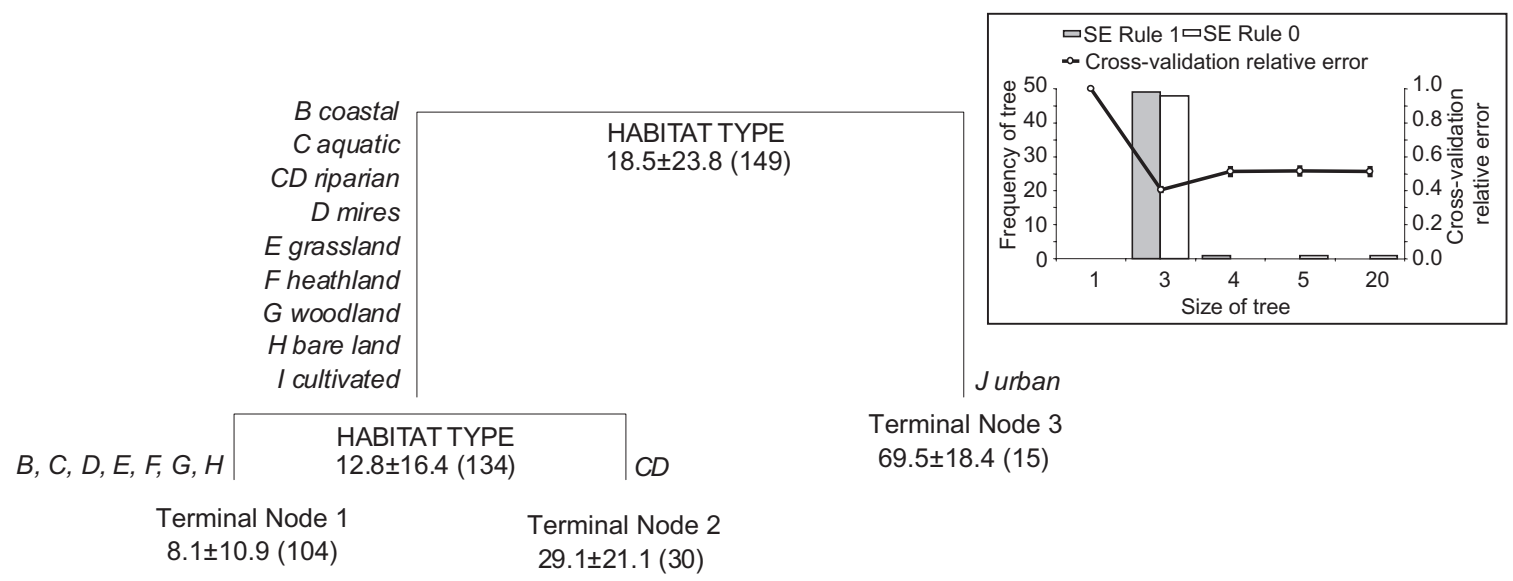

(b) Insects

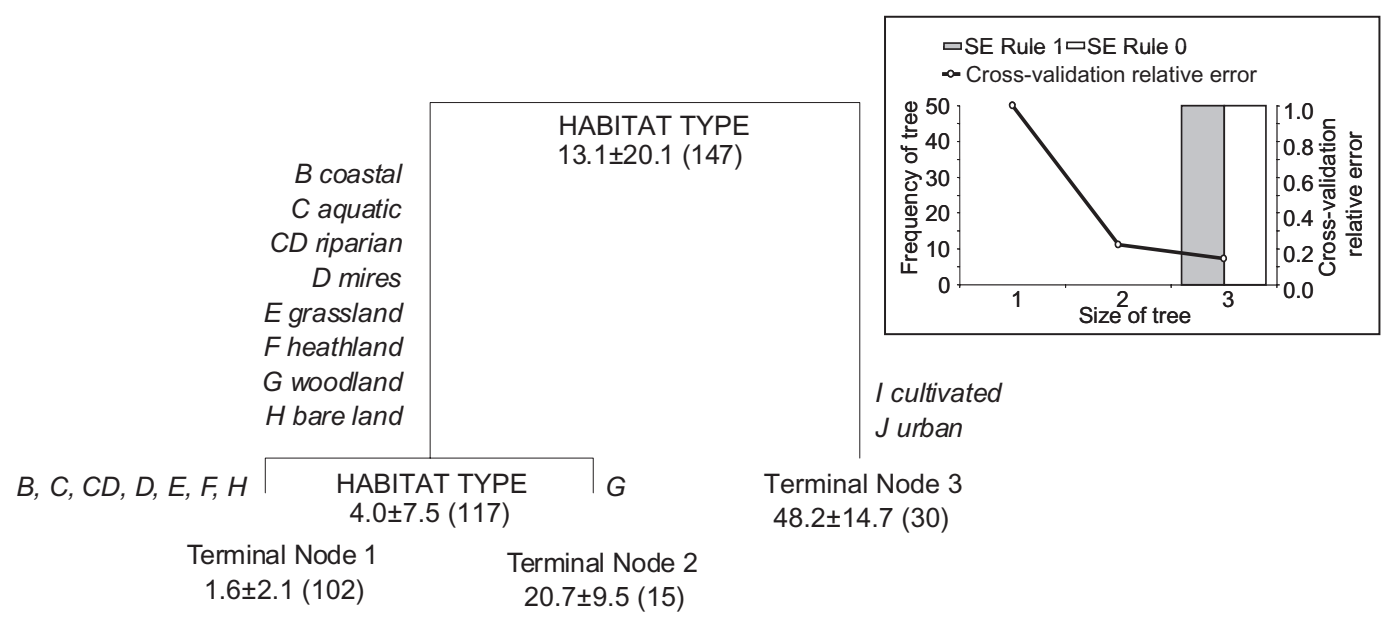

Figure 3 Best regression trees describing which factors determine the proportion of regional alien biota that invade in European habitats expressed as the percentage of the total number of naturalized alien species in a region that occur in the particular habitat: (a) plants (total explained variance $\left.r^{2}=0.636\right)$, (b) insects $\left(r^{2}=0.861\right)$, (c) herptiles $\left(r^{2}=0.271\right)$, (d) birds $\left(r^{2}=0.542\right)$, and (e) mammals $\left(r^{2}=0.479\right)$. Each node of the tree is described by the splitting variable and its split value, mean and standard deviation of the percentage of the species, and the number of samples (regional data sets) at that node. The vertical depth of each node is proportional to its improvement value that corresponds to explained variance at each node. For mammals (e), the best regression tree is presented with a specified minimum number of samples at the terminal nodes equal to 30 and removing the lower terminal nodes that explained only $5 \%$ of its total explained variance. Insets: cross-validation processes for selection of the best regression trees. Lines show a single representative 10-fold cross-validation of the most frequent (modal) best trees with standard error (SE) estimates of each tree size. Bar charts are the numbers of the optimal trees of each size (Frequency of tree) selected from a series of 50 cross-validations based on the minimum cost tree, which minimizes the cross-validated error (white, SE rule 0), and 50 cross-validations based on the SE rule 1 (grey, SE rule 1), which minimizes the cross-validated error within one standard error of the minimum. The most frequent (modal) trees have three (a, b), two (c), six (d), and five (e) terminal nodes.

plants. Alien birds were most represented in cultivated, aquatic, riparian and woodland habitats (Fig. 3d).

The patterns for herptiles (Fig. 3c) and mammals (Fig. 3e) were more complex, because insularity and latitude codetermined the proportions of the total alien species number in a region that occur in individual habitats. Except for coastal habitats, herptiles were relatively better represented at northern latitudes $\left(>50^{\circ}\right)$; this contributed $28 \%$ to the total variance explained by the best regression tree. The remaining $72 \%$ of the variance explained by habitat was due to the proportions of herptiles in aquatic, riparian, woodland and cultivated habitats being higher than in other habitats, among which there was further differentiation at $50^{\circ} \mathrm{N}$ latitude (Fig. $3 \mathrm{c}$ ).

The initial best regression tree for mammals (not shown) explained $83.6 \%$ of the total variance, to which habitat contributed $61 \%$, latitude $28 \%$ and insularity $11 \%$. There was a striking 
(c) Herptiles

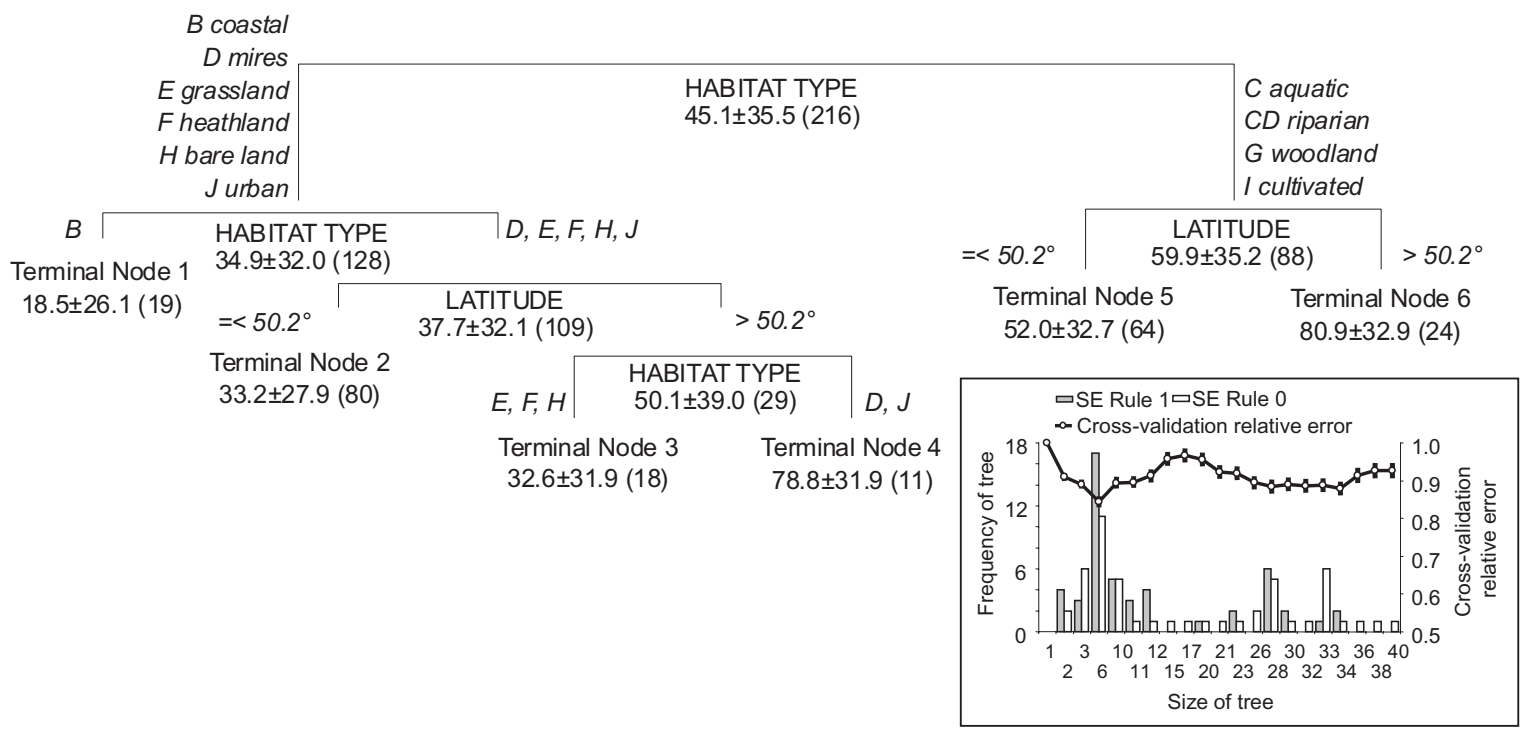

(d) Birds

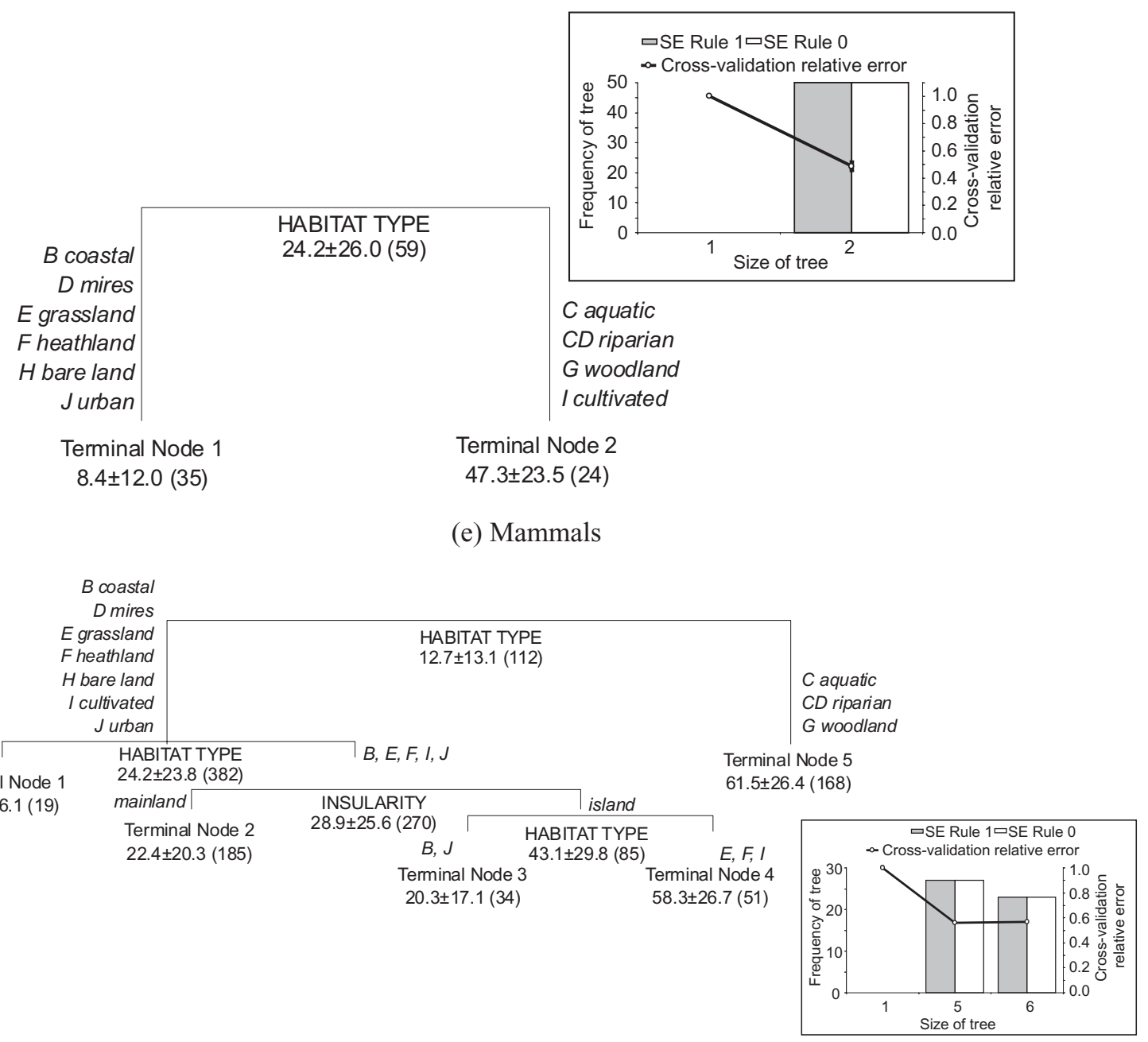

Figure 3 Continued 
pattern of repeated splitting of the nodes according to latitude, which suggests a linear dependence of the proportions of alien mammals on latitude. A corresponding ANCOVA analysis (Table 3, mammals) revealed a significant decrease of the proportions of alien mammals towards the north (regression slope on latitude \pm standard error: $-0.0029 \pm 0.0014 ; t=2.06 ; P=$ 0.04 ). The pattern of proportional representation of mammals with latitude thus appeared converse to herptiles. A simplified best tree, with size constrained to have at least 30 samples at each terminal node, produced 13 terminal nodes and explained 54\% of variance, to which habitat contributed $80 \%$, insularity $17 \%$ and latitude only $3 \%$. The final best tree, in which $5 \%$ of its total variance at the lowest terminal nodes was removed by setting a complexity parameter (Fig. 3e), contained only the habitat (89\% of the total explained variance) and insularity. The overall effect of latitude thus decreased with the gradual simplification of the best tree. Alien mammals were most represented in woodland, aquatic and riparian habitats, and least on bare land and in mires. In the remaining habitats, mammals were proportionally more common on islands than on mainland, and on islands more represented in grasslands and heathland/scrub than in cultivated, coastal and urban habitats (Fig. 3e).

\section{DISCUSSION}

\section{Measures of habitat invasion}

Although recent studies for plants indicate that habitats are among the most important determinants of the level of invasion (Chytrý et al., 2008a), a complete understanding of the role of habitats in controlling the pattern of invasion at various scales is still constrained by limited data availability for other taxa. To improve our understanding of biological invasions and their prediction, the role of habitats needs to be taken into account (Lodge, 1993), because under the conditions of ongoing global change, it is likely that the patterns of habitat availability will change (Rounsevell et al., 2006) and in some habitats invasions may be facilitated in the future.

We applied several measures of habitat invasions. To account for different areas and make possible comparison across regions, we used alien species densities per unit area. To obtain a relative measure of invasions into individual habitats, we used the proportion of the total alien species present in a region that invade in a given habitat. This measure allows comparison among taxonomic groups that markedly differ in the number of alien species and quantifies alien species richness that an individual habitat might potentially encounter. Although the habitats are invaded to a different degree, in terms of the number of alien species they harbour, they do not differ in rates at which they encounter new species with increasing habitat area. Regarding differences in the rate of accumulation with increasing habitat area of species from different taxonomic groups, alien insects accumulate fastest, followed by plants and vertebrates. Had the habitats in individual regions been saturated by alien species, the proportions of the total alien species numbers in regions would provide some indication of habitat invasibility. However, the relationships between alien species richness and habitat area did not approach an asymptote and therefore there is no indication of saturation of individual habitats by alien species; this confirms the conclusions of Stohlgren et al. (2008) who found no indication of saturation at the level of habitat type by alien plant species for US state, regional or national floras.

Moreover, our measure based on the proportion of alien species cannot be taken as a measure of habitat invasibility as defined by Lonsdale (1999) because it does not include a measure of propagule pressure (e.g. Lockwood et al., 2005). Unfortunately, the information on propagule pressure or its proxies, commonly used in invasion literature (Blackburn \& Duncan, 2001; Cassey et al., 2004; Taylor \& Irwin, 2004; Jeschke \& Strayer, 2006; Křivánek et al., 2006; Gravuer et al., 2008; Chytrý et al., 2008a; Dawson et al., 2009), is rarely available at the regional scale for the range of taxonomic groups considered in our study and for individual habitat. In the future it may be possible to account for the pathways of introduction of individual species as a proxy for propagule pressure (Hulme et al., 2008). For example, Hulme (2007) highlighted that species with high propagule pressure (e.g. introduced deliberately for agriculture, silviculture or horticulture, or escaped from gardens) were found in almost all habitats in Scotland, whereas contaminants (e.g. seed contaminants) or stowaways were far less widespread and were usually found in anthropogenic rather than semi-natural ecosystems. Due to the absence of information on propagule pressure in our data, the patterns we found are interpreted in terms of the level of invasion occurring in individual habitats rather than their vulnerability to invasion.

\section{Comparing invasions in different habitats across taxonomic groups}

We provide the first quantitative assessment of invasions of habitat types by alien plants and animals at a continental scale. Some distinct patterns of habitat invasions can be recognized among taxonomic groups. Both plants and insects exhibit high levels of invasions in human-made habitats, both urban and cultivated. Among these human-made habitats, parks and gardens appear to be the dominant habitat for alien insects. Large numbers of alien species are a general feature of cultivated habitats that are also suitable for invasions by birds and herptiles, leaving mammals as the only group that is not so markedly successful there; this may be due to the fact that many of the worst agricultural alien mammal pests had been introduced to some regions before 1500. Mammals and herptiles form another distinct group, particularly well represented in woodland, aquatic and riparian habitats. The latter two habitats are also frequently used by birds, but this group is most often found on cultivated land, parks and gardens. Coastal habitats, mires, bogs and fens, grassland and heathland/scrub are generally less invaded than the habitats mentioned above. If the level of invasion was controlled for habitat area in the region, the ranking of habitats was similar to that based on the alien species numbers; the only exception to this pattern was riparian habitats which appeared highly invaded by all groups of taxa except insects. For 
plants, such species numbers from riparian habitats were almost as high as for urban habitats. It can be hypothesized that this is due to efficient dispersal by water, creating permanently high propagule pressure of alien species associated with this habitat (Truscott et al., 2006; Richardson et al., 2007; Kowarik \& Säumel, 2008), and frequent disturbance which opens extant communities to the invasion by aliens (Davis et al., 2000).

The highly significant correlation between the numbers of alien insects and plants is likely to be related to the prevailing phytophagous feeding habit of alien insects (48\% of all alien insects in Europe; Roques et al., 2009). The trade in ornamental plants, and more generally horticulture, appeared to be the dominant pathway of introduction for both alien plants (Lambdon et al., 2008) and insects arriving as contaminants of these plants (38\% of the introductions; Roques et al., 2009). Moreover, a large number of the phytophagous insects are still exclusively present on their original, exotic host plant and have not switched to natives, which is the case for $46.4 \%$ of the alien insect species related to woody plants (A. Roques, unpublished).

The contrasting invasion patterns of the two groups of taxa (plants and insects versus vertebrates) are complementary in terms of habitat use. The parts of the European landscape supporting many species of one of these groups of alien biota include habitats intensively disturbed by human activities, riparian habitats and surface waters, which are often exposed to natural disturbances, as well as woodland and forest. On the other hand, grassland, heathland/scrub, mires, bogs and fens and sparsely vegetated inland sites are much less invaded. For plants, it has been proposed that at a local scale, habitats are more vulnerable to invasions if they experience pulses of free resources (Davis et al., 2000). The largest numbers or densities of alien plant species were found in urban, cultivated and riparian habitats, which are also heavily invaded locally and involve frequent disturbances and distinct pulses of resources, especially nutrients (Chytrý et al., 2008b).

It is also a common observation that alien insects are far more abundant in disturbed, human-made habitats, including forest plantations, than in less disturbed habitats. Three hypotheses may be proposed (Simberloff, 1986; Kenis et al., 2007). Firstly, natural enemies and competitors are more prevalent in natural habitats than in disturbed ones (i.e. biotic resistance; Elton, 1958). Secondly, establishments of alien insects are more likely to be detected in agricultural and other human-made habitats because these are studied more thoroughly than natural habitats. Finally, and most importantly, insects linked to human environments and activities, in particular plant pests, are more likely to be carried into a new area by human transport than insects living in natural environments. Indeed, the majority of insects intercepted at ports of entry are agricultural, forest or domestic pests (Kenis et al., 2007).

The variation in invasibility and level of invasion of habitat types by vertebrates is much less studied than in plants and insects. There is thus no convincing theory of what to expect. One reason why vertebrates were more common in woodland, aquatic and riparian habitats than plants and insects may lie in their different history of introduction. In contrast to plants and insects, vertebrates were mostly intentionally introduced to Europe, often for hunting, fur farming or as 'improvement' of the native fauna (Hulme et al., 2008; Genovesi et al., 2009, 2009). A large number of species were thus associated with woodland (e.g. deer) or wet habitats (e.g. waterfowl) in their native range. For example, $60 \%$ of alien mammals introduced to Europe can be found in woodland and forest habitats in their native range (Bacher et al. unpublished). Thus, even if it might appear that these habitats have a lower resistance to vertebrate invasions, this may come from the fact that species associated with these habitats were released with higher frequency than in human-made habitats. The contrasting pattern in use of habitats strongly and less disturbed by humans, with alien plants and insects typical of the former and vertebrates of the latter, can be interpreted in terms of different behaviour and relationship with humans. Habitat choice of many vertebrate species, mammals in particular, is likely to be driven by avoidance of humans; this is not the case with plants and insects.

\section{Geographical factors fine-tune habitat invasions by taxonomic groups}

Habitat and taxonomic group explain most variation in the proportions of alien species, of their total numbers in a region, recorded in individual habitat types. However, the basic pattern determined by these factors is fine-tuned by geographical variables, namely whether the habitat is on the mainland or an island, and by latitude. The positive effect of insularity found for alien mammals corresponds to well-established knowledge that islands are more prone to invasions than mainlands (Lonsdale, 1999; Sax, 2001; Brown \& Sax, 2004; Sax \& Gaines, 2005; Daehler, 2006; Gimeno et al., 2006; Blackburn et al., 2008); this is thought to be due to the lower resistance of species-poor communities to invaders and the effect of smaller native species pools on islands (e.g. Denslow, 2003; Hulme, 2004; Herben, 2005) resulting from isolation, or a more intensive effect of human-related environmental driving forces compared to the mainland (Gimeno et al., 2006). As we analysed numbers of alien species in particular habitats standardized relative to the total number of alien species in the region, the differences between regions mainly result from different niche breaths of alien species in particular regions. That more alien species are found in island habitats than in mainland habitats means that on average on islands they occur in a wider range of habitats than on the mainland.

The effect of latitude is more complex, because latitude correlates with many other factors such as climate and species range sizes (Sax, 2001). For mammals, it explains a substantial percentage of variation in the proportions of the total numbers of alien species in a region, and appears as a significant predictor in many splitting nodes of the initial best regression tree. A possible explanation could be that the pattern of current invasions of mammals to a large extent results from intentional introductions and releases (Genovesi et al., 2009) and these introductions occurred across latitudes; therefore the natural effect on invasion patterns of factors changing with latitude might have 
been disrupted, which makes it rather inconsistent and difficult to interpret (Solarz et al., 2010). Yet in general the proportions of alien mammals decrease towards the north, which indicates decreasing niche breath with latitude and corresponds to a similar pattern of decreasing invasion success with latitude previously reported for plants, although obtained by using a different measure (the percentage of naturalized species from the total number of introduced aliens; Pyšek \& Richardson, 2006).

The opposite pattern found for herptiles, an increase above $50^{\circ} \mathrm{N}$ latitude, is difficult to explain; it is possible that the latitudinal effect is confounded by intentional releases that are also an important pathway in this group (Bomford et al., 2009). Although in the past, southern European countries received more attempts to introduce a wider variety of alien amphibians and reptiles than areas further north because of more adverse climatic conditions at higher latitudes (Kark et al., 2009), those fewer releases in the more northerly located parts of the continent were of species better able to cope with the local climate. Climate match is a crucial factor determining establishment in this poikilothermic taxonomic group (Bomford et al., 2009; Kraus, 2009), and climate may limit alien herptiles at both ends of the temperature spectrum. For a species from temperate regions on other continents, it may be easier to establish in the still relatively mild climate of the $50^{\circ} \mathrm{N}$ latitude, corresponding to, for example, the UK, than in hot and dry regions in southern Europe. Another explanation could be that $46 \%$ of alien herptiles successfully introduced to Europe have at least part of their range somewhere else in Europe (Kark et al., 2009). It is likely that it was rather southern European species that were introduced to the north than the other way round. Therefore, southern amphibian and reptile fauna might have been enriched by species from other continents, while northern fauna had influx from both outside of Europe and the south of the continent.

\section{CONCLUSIONS: CAN WE FIND A COMMON CURRENCY OF BIOLOGICAL INVASIONS IN EUROPE?}

Data available for the groups of taxa assessed differ in the scale and geographical area targeted and their quality varies among taxa and regions. Nevertheless, the data set is representative of the habitat types and functional groups of the alien taxa analysed. Even for plants, where the gap in the knowledge of species affinity to particular habitat types is the largest, $75 \%$ of species were classified, and in all other groups the percentage of species with known habitat affinities exceeds $95 \%$ of the total number of aliens.

Our paper provides a broad overview of patterns of invasive species associated with broad habitat types, insularity and latitude. Finer habitat resolution was impossible to adopt due to data constraints, as information on species habitat affinities is not available at a finer scale for a range of taxonomic groups and the whole of Europe. The coarse classification of habitats used implies that some aspects of habitat invasions could not be assessed with the current data, such as habitat heterogeneity in space and time (e.g. various successional stages and vegetation gradients occurring within particular habitats). This applies especially to human-made habitats which consist of a mixture of microhabitats with a considerable temporal dynamics, each of them contributing to the number of naturalized alien species (Pyšek et al., 2004a; Lososová \& Simonová, 2008). It is obvious that the relative importance of each type of habitat has largely changed since 1500 , the beginning of the period of invasion addressed in our study. However, more than $60 \%$ of the alien insect species, for example, arrived during the last 50 years and faced present-day habitats (Roques et al., 2009), and the same is true for c. 25\% of alien plants (Lambdon et al., 2008). Nevertheless, although the current assemblages of alien species are co-determined by a number of factors such as land-use history, climate, microclimate, disturbance, water and nutrient supply, and human-aided establishment (e.g. Stohlgren et al., 2005, 2006), this study confirms that habitat is a major determinant of the level of invasion as shown previously for plants (Chytrý et al., 2008a). This is because habitats integrate many environmental gradients, which makes them a suitable proxy for explaining much of the spatial variation in invasions.

Our results show that when invasions in Europe are assessed using habitats, there are two ecologically distinct groups (plants and insects versus vertebrates) with strikingly different habitat affinities of their alien members. Numbers of alien species in a habitat are correlated within these two groups, i.e. insects with plants, and herptiles, birds and mammals with each other, as previously shown for regional alien species richness (McKinney, 2006). One potential practical implication of these results concerns prioritization of monitoring efforts - the data collected for one group, vertebrates for example, could be used to predict invasion of a habitat type by other vertebrate groups with reasonable precision, and the same holds for inferring the level of habitat invasion by insects from data on plants and vice versa (Hulme, 2006).

Moreover, the existence of the two distinct groups invading in different, yet to some extent complementary, suites of habitats makes the overall assessment of habitat invasions in Europe possible, and shows that only a few habitat types are little threatened by invasions. The present paper identifies habitat as a major determinant of alien species invasions. As shown previously for plants, knowledge of the occurrence of alien species in habitats provides a solid basis for spatially explicit risk assessment of biological invasions (Chytrý et al., 2008a, 2009).

\section{ACKNOWLEDGEMENTS}

This work was supported by the FP6 European Union projects ALARM (GOCE-CT-2003-506675; Settele et al., 2005) and DAISIE (SSPI-CT-2003-511202; DAISIE, 2009) and projects MSM0021622416, MSM0021620828 and LC06073 from the Ministry of Education of the Czech Republic, AV0Z60050516 from the Academy of Sciences of the Czech Republic; and MONTES-CSD2008-00040 from the Spanish Ministry of Sciences and Innovation. We thank Erica Fleishman and two anonymous reviewers for their comments on the manuscript. 


\section{REFERENCES}

Alvarez, M.E. \& Cushman, J.H. (2002) Community-level consequences of a plant invasion: effects of three habitats in coastal California. Ecological Applications, 12, 1434-1444.

Blackburn, T.M. \& Duncan, R.P. (2001) Establishment patterns of exotic birds are constrained by non-random patterns in introduction. Journal of Biogeography, 28, 927-939.

Blackburn, T.M., Cassey, P. \& Lockwood, J.L. (2008) The island biogeography of exotic bird species. Global Ecology and Biogeography, 17, 246-251.

Bomford, M., Kraus, F., Barry, S.C. \& Lawrence, E. (2009) Predicting establishment success for alien reptiles and amphibians: a role for climate matching. Biological Invasions, 11, 713-724.

Bossard, M., Feranec, J. \& Otahel, J. (2000) CORINE land cover technical guide - addendum 2000. European Environment Agency, Copenhagen.

Breiman, L., Friedman, J.H., Olshen, R.A. \& Stone, C.G. (1984) Classification and regression trees. Wadsworth International Group, Belmont, CA.

Brown, J.H. \& Sax, D.F. (2004) An essay on some topics concerning invasive species. Austral Ecology, 29, 530-536.

Byers, J.E. (2002) Physical habitat attribute mediates biotic resistance to non-indigenous species invasion. Oecologia, 130, 146-156.

Cassey, P., Blackburn, T.M., Sol, D., Duncan, R.P. \& Lockwood, J.L. (2004) Global patterns of introduction effort and establishment success in birds. Proceedings of the Royal Society B: Biological Sciences, 271 (Suppl. 6), 405-408.

Chytrý, M., Pyšek, P., Tichý, L., Knollová, I. \& Danihelka, J. (2005) Invasions by alien plants in the Czech Republic: a quantitative assessment across habitats. Preslia, 77, 339-354.

Chytrý, M., Jarošík, V., Pyšek, P., Hájek, O., Knollová, I., Tichý, L. \& Danihelka, J. (2008a) Separating habitat invasibility by alien plants from the actual level of invasion. Ecology, 89, 1541-1553.

Chytrý, M., Maskell, L.C., Pino, J., Pyšek, P., Vilà, M., Font, X. \& Smart, S.M. (2008b) Habitat invasions by alien plants: a quantitative comparison among Mediterranean, subcontinental and oceanic regions of Europe. Journal of Applied Ecology, 45, 448-458.

Chytrý, M., Pyšek, P., Wild, J., Pino, J., Maskell, L.C. \& Vilà, M. (2009) European map of alien plant invasions, based on the quantitative assessment across habitats. Diversity and Distributions, 15, 98-107.

Crawley, M.J. (1987) What makes a community invasible? Colonization, succession and stability (ed. by A.J. Gray, M.J. Crawley and P.J. Edwards), pp. 429-453. Blackwell Scientific Publications, Oxford.

Crawley, M.J. (1993) GLIM for ecologists. Blackwell Scientific Publications, Oxford.

Crawley, M.J. (2002) Statistical computing. An introduction to data analysis using S-Plus. John Wiley, Chichester, UK.

Daehler, C.C. (2006) Invasibility of tropical islands by introduced plants: partitioning the influence of isolation and propagule pressure. Preslia, 78, 389-404.
DAISIE (2009) Handbook of alien species in Europe. Springer, Dordrecht.

Davies, C.E., Moss, D. \& Hill, M.O. (2004) EUNIS habitat classification, revised 2004. European Environment Agency, Copenhagen and European Topic Centre on Nature Protection and Biodiversity, Paris.

Davis, M.A., Grime, J.P. \& Thompson, K. (2000) Fluctuating resources in plant communities: a general theory of invasibility. Journal of Ecology, 88, 528-534.

Dawson, W., Burslem, D.F.R. \& Hulme, P.E. (2009) Herbivory is related to taxonomic isolation, but not to invasiveness of tropical alien plants. Diversity and Distributions, 15, 141-147.

De'ath, G. \& Fabricius, K.E. (2000) Classification and regression trees: a powerful yet simple technique for ecological data analysis. Ecology, 81, 3178-3192.

Denslow, J.S. (2003) Weeds in paradise: thoughts on the invasibility of tropical islands. Annals of the Missouri Botanical Garden, 90, 119-127.

Elton, C.S. (1958) The ecology of invasions by animals and plants. Methuen, London.

García-Robledo, C.A. \& Murcia, C. (2005) Comparative habitat susceptibility to invasion by Chinese ash (Fraxinus chinensis: Oleaceae) in a tropical Andean landscape. Biological Invasions, 7, 405-415.

Gaston, K.J. \& Blackburn, T.M. (2000) Pattern and process in macroecology. Blackwell Science, Oxford.

Genovesi, P., Bacher, S., Kobelt, M., Pascal, M. \& Scalera, R. (2009) Alien mammals of Europe. Handbook of alien species in Europe (ed. by DAISIE), pp. 119-128. Springer, Dordrecht.

Gimeno, I., Vilà, M. \& Hulme, P.E. (2006) Are islands more susceptible to plant invasion than continents? A test using Oxalis pes-caprae L. in the western Mediterranean. Journal of Biogeography, 33, 1559-1565.

Gravuer, K., Sullivan, J.J., Williams, P.A. \& Duncan, R.P. (2008) Strong human association with plant invasion success for Trifolium introductions to New Zealand. Proceedings of the National Academy of Sciences USA, 105, 6344-6349.

Hall, L.S., Krausman, P.R. \& Morrison, M.L. (1997) The habitat concept and a plea for standard terminology. Wildlife Society Bulletin, 25, 173-182.

Hejda, M., Pyšek, P. \& Jarošík, V. (2009) Impact of invasive plants on the species richness, diversity and composition of invaded communities. Journal of Ecology, 97, 393-403.

Herben, T. (2005) Species pool size and invasibility of island communities: a null model of sampling effects. Ecology Letters, 8, 909-917.

Hierro, J.L., Maron, J.L. \& Callaway, R.M. (2005) A biogeographical approach to plant invasions: the importance of studying exotics in their introduced and native range. Journal of Ecology, 93, 5-15.

Hood, W.G. \& Naiman, R.J. (2000) Vulnerability of riparian zones to invasion by exotic vascular plants. Plant Ecology, 148, 105-114.

Hulme, P.E. (2004) Invasions, islands and impacts: a Mediterranean perspective. Island ecology (ed. by J.M. Fernández- 
Palacios and C. Morici), pp. 359-383. Asociación Española de Ecología Terrestre, La Laguna.

Hulme, P.E. (2006) Beyond control: wider implications for the management of biological invasions. Journal of Applied Ecology, 43, 835-847.

Hulme, P.E. (2007) Biological invasions in Europe: drivers, pressures, states, impacts and responses. Biodiversity under threat (ed. by R. Hester and R.M. Harrison), pp. 56-80. Royal Society of Chemistry, Cambridge.

Hulme, P.E., Bacher, S., Kenis, M., Klotz, S., Kühn, I., Minchin, D., Nentwig, W., Olenin, S., Panov, V., Pergl, J., Pyšek, P., Roques, A., Sol, D., Solarz, W. \& Vilà, M. (2008) Grasping at the routes of biological invasions: a framework to better integrate pathways into policy. Journal of Applied Ecology, 45, 403-414.

Inderjit (2005) Plant invasions: habitat invasibility and dominance of invasive plant species. Plant and Soil, 277, 1-5.

Jeschke, J.J. \& Strayer, D.L. (2006) Determinants of vertebrate invasion success in Europe and North America. Global Change Biology, 12, 1608-1619.

Kark, S., Solarz, W., Chiron, F., Clergeau, P. \& Shirley, S. (2009) Alien birds, amphibians and reptiles of Europe. Handbook of alien species in Europe (ed. by DAISIE), pp. 105-118. Springer, Dordrecht.

Kenis, M., Rabitsch, W., Auger-Rozenberg, M.-A. \& Roques, A. (2007) How can alien species inventories and interception data help us prevent insect invasions? Bulletin of Entomological Research, 97, 489-502.

Kowarik, I. \& Säumel, I. (2008) Water dispersal as an additional pathway to invasions by the primarily wind-dispersed tree Ailanthus altissima. Plant Ecology, 198, 241-252.

Kraus, F. (2009) Alien reptiles and amphibians: a scientific compendium and analysis. Springer, Dordrecht.

Křivánek, M., Pyšek, P. \& Jarošík, V. (2006) Planting history and propagule pressure as predictors of invasions by woody species in a temperate region. Conservation Biology, 20, 14871498.

Lambdon, P.W., Pyšek, P., Basnou, C. et al. (2008) Alien flora of Europe: species diversity, temporal trends, geographical patterns and research needs. Preslia, 80, 101-149.

Lockwood, J.L., Cassey, P. \& Blackburn, T. (2005) The role of propagule pressure in explaining species invasions. Trends in Ecology and Evolution, 20, 223-228.

Lodge, D.M. (1993) Species invasions and deletions: community effects and responses to climate and habitat change. Biotic interactions and global change (ed. by P.M. Kareiva, J.G. Kingsolver and R.B. Huey), pp. 367-387. Sinauer, Sutherland.

Lonsdale, W.M. (1999) Global patterns of plant invasions and the concept of invasibility. Ecology, 80, 1522-1536.

Lososová, Z. \& Simonová, D. (2008) Changes during the 20th century in species composition of synanthropic vegetation in Moravia (Czech Republic). Preslia, 80, 291-305.

McCullagh, P. \& Nelder, J.A. (1989) Generalized linear models. Chapman \& Hall, London.

McKinney, M.L. (2006) Correlated non-native species richness of birds, mammals, herptiles and plants: scale effects of area, human population and native plants. Biological Invasions, 8, 415-425.

Maskell, L.C., Firbank, L.G., Thompson, K., Bullock, J.M. \& Smart, S.M. (2006) Interactions between non-native plant species and the floristic composition of common habitats. Journal of Ecology, 94, 1052-1060.

Pyšek, P. \& Richardson, D.M. (2006) The biogeography of naturalization in alien plants. Journal of Biogeography, 33, 2040 2050.

Pyšek, P., Chocholoušková, Z., Pyšek, A., Jarošík, V., Chytrý, M. \& Tichý, L. (2004a) Trends in species diversity and composition of urban vegetation over three decades. Journal of Vegetation Science, 15, 781-788.

Pyšek, P., Richardson, D.M. \& Williamson, M. (2004b) Predicting and explaining plant invasions through analysis of source area floras: some critical considerations. Diversity and Distributions, 10, 179-187.

Pyšek, P., Jarošík, V., Chytrý, M., Kropáč, Z., Tichý, L. \& Wild, J. (2005) Alien plants in temperate weed communities: prehistoric and recent invaders occupy different habitats. Ecology, 86, 772-785.

Pyšek, P., Hulme, P.E. \& Nentwig, W. (2009) Glossary of the main technical terms used in the handbook. Handbook of alien species in Europe (ed. by DAISIE), pp. 375-379. Springer, Dordrecht.

Quinn, G.P. \& Keough, M.J. (2002) Experimental design and data analysis for biologists. Cambridge University Press, Cambridge.

Radford, I.J., Nicholas, M., Tiver, F., Brown, J. \& Kriticos, D. (2002) Seedling establishment, mortality, tree growth rates and vigour of Acacia nilotica in different Astrebla grassland habitats: implications for invasion. Austral Ecology, 27, 258268.

Richardson, D.M. \& Pyšek, P. (2006) Plant invasions: merging the concepts of species invasiveness and community invasibility. Progress in Physical Geography, 30, 409-431.

Richardson, D.M., Holmes, P.M., Esler, K.J., Galatowitsch, S.M., Stromberg, J.C., Kirkman, S.P., Pyšek, P. \& Hobbs, R.J. (2007) Riparian vegetation: degradation, alien plant invasions, and restoration prospects. Diversity and Distributions, 13, 126139.

Richardson, D.M., Pyšek, P., Rejmánek, M., Barbour, M.G., Panetta, F.D. \& West, C.J. (2000) Naturalization and invasion of alien plants: concepts and definitions. Diversity and Distributions, 6, 93-107.

Roques, A., Rabitsch, W., Rasplus, J.Y., Lopez-Vaamonde, C., Nentwig, W. \& Kenis, M. (2009) Alien terrestrial invertebrates of Europe. Handbook of alien species in Europe (ed. by DAISIE), pp. 63-79. Springer, Dordrecht.

Rounsevell, M.D.A., Reginster, I., Araújo, M.B., Carter, T.R., Dendoncker, N., Ewert, F., House, J.I., Kankaanpää, S., Leemans, R., Metzger, M.J., Schmit, C., Smith, P. \& Tuck, G. (2006) A coherent set of future land use change scenarios for Europe. Agriculture, Ecosystems and Environment, 114, 57-68. Ruiz, G.M., Carlton, J.T., Grosholz, E.D. \& Hines, A.H. (1997) Global invasions of marine and estuarine habitats by non- 
indigenous species: mechanisms, extent and consequences. American Zoologist, 37, 621-632.

Sádlo, J., Chytrý, M. \& Pyšek, P. (2007) Regional species pools of vascular plants in habitats of the Czech Republic. Preslia, 79, 303-321.

Sax, D.F. (2001) Latitudinal gradients and geographic ranges of exotic species: implications for biogeography. Journal of Biogeography, 28, 139-150.

Sax, D.F. \& Gaines, S.D. (2005) The biogeography of naturalised species and the species-area relationship: reciprocal insights to biogeography and invasion biology. Conceptual ecology and invasions biology: reciprocal approaches to nature (ed. by M.W. Cadotte, S.M. McMahon and T. Fukami), pp. 449-480. Kluwer, Dordrecht.

Settele, J., Hammen, V., Hulme, P. et al. (2005) ALARM - Assessing LArge-scale environmental Risks for biodiversity with tested Methods. GAIA, 14, 69-72.

Simberloff, D. (1986) Introduced insects: a biogeographic and systematic perspective. Ecology of biological invasions of North America and Hawaii (ed. by H.A. Mooney and J.A. Drake), pp. 3-26. Springer, New York.

Slootweg, J., Hettelingh, J.-P., Tamis, W.L.M. \& Zelfde, M. (2005) Harmonizing European land cover maps. European critical loads and dynamic modelling (ed. by M. Posch, J. Slootweg and J.-P. Hettelingh), pp. 47-70. Netherlands Environmental Assessment Agency (MNP), Bilthoven.

Sokal, R. \& Rohlf, F.J. (1995) Biometry, 3rd edn. Freeman, San Francisco.

Solarz, W., Król, W., Bacher, S., Nentwig, W. \& Sol, D. (2010) Terrestrial alien vertebrates in Europe. Atlas of biodiversity risk (ed. by J. Settele, L. Penev, T. Georgiev, R. Grabaum, V. Grobelnik, V. Hammen, S. Klotz, M. Kotarac and I. Kühn), in press. Pensoft, Sofia and Moscow.

Southwood, T.R.E. (1977) Habitat, the templet for ecological strategies? Journal of Animal Ecology, 46, 337-365.

Steinberg, G. \& Colla, P. (1995) CART: tree-structured nonparametric data analysis. Salford Systems, San Diego.

Stohlgren, T.J., Guenther, D.A., Evangelista, P.H. \& Alley, N. (2005) Patterns of plant species richness, rarity, endemism, and uniqueness in an arid landscape. Ecological Applications, 15, 715-725.

Stohlgren, T.J., Jarnevich, C.S., Chong, G.W. \& Evangelista, P.H. (2006) Scale and plant invasions: a theory of biotic acceptance. Preslia, 78, 405-426.

Stohlgren, T.J., Barnett, D.T., Jarnevich, C.S., Flather, C. \& Kartesz, J. (2008) The myth of plant species saturation. Ecology Letters, 11, 313-326.

Taylor, B.W. \& Irwin, R.E. (2004) Linking economic activities to the distribution of exotic plants. Proceedings of the National Academy of Sciences USA, 101, 17725-17730.

Thackway, R. \& Lesslie, R. (2006) Reporting vegetation condition using the Vegetation Assets, States, and Transitions (VAST) framework. Ecological Management and Restoration, 7, S53-S62.

Truscott, A.-M., Soulsby, C., Palmer, S.C.F., Newell, L. \& Hulme, P.E. (2006) The dispersal characteristics of the invasive plant
Mimulus guttatus and the ecological significance of increased occurrence of high-flow events. Journal of Ecology, 94, 10801091.

Vilà, M., Pino, J. \& Font, X. (2007) Regional assessment of plant invasions across different habitat types. Journal of Vegetation Science, 18, 35-42.

Zalba, S.M., Sonaglioni, M.I., Compagnoni, C.A. \& Belenguer, C.J. (2000) Using a habitat model to assess the risk of invasion by an exotic plant. Biological Conservation, 93, 203208.

\section{SUPPORTING INFORMATION}

Additional Supporting Information may be found in the online version of this article:

Appendix S1 Overview of the numbers of naturalized alien species occurring in European terrestrial and aquatic habitats. Total number of species recorded/alien species density (number of species per log habitat area) are shown. Note that species totals may exceed the sum of habitat species numbers since some species occur in more than one habitat. Regions within taxonomic groups are listed alphabetically. Abbreviations of taxonomic groups: ins - insects, mam - mammals, her - herptiles; $\mathrm{x}$ - habitat not present. Blank cells indicate that no naturalized alien species are reported from the habitat in the given region. See text for full names of habitats.

Appendix S2 An alternative generalized linear model with loglink function and Poisson errors of the relationship between alien species numbers ( $y$, numbers shown only for the range of predicted values) and habitat area ( $\mathrm{x}, \mathrm{ln}$ transformed). Taxonomic groups: symbols and heavy fitted lines; habitat types (in italics): light fitted lines. The model does not enable unequivocal factor level reduction for intercepts of the individual habitats; consequently, only woodland and coastal habitats with the same intercepts are collapsed together. Insects (diamonds): $\mathrm{yl}=$ $\exp (-0.99+0.33 \mathrm{x}) ;$ plants (dashes): $\mathrm{y} 2=\exp (1.53+0.11 \mathrm{x})$; aquatic habitats: $\mathrm{y} 3=\exp (-0.11+0.15 \mathrm{x})$; urban habitats: $\mathrm{y} 4=$ $\exp (0.69+0.15 x ;)$ riparian habitats: $y 5=\exp (0.11+0.15 x)$; arable land habitats: $\mathrm{y} 6=\exp (-0.28+0.15 \mathrm{x})$; herptiles (squares), birds (crosses), mammals (triangles), coastal and woodland habitats: $\mathrm{y} 7=\exp (-0.49+0.15 \mathrm{x})$; mires: $\mathrm{y} 8=$ $\exp (-0.84+0.15 \mathrm{x})$; heathlands/scrub: $\mathrm{y} 9=\exp (-0.86+0.15 \mathrm{x})$; grasslands: $\mathrm{y} 10=\exp (-1.06+0.15 \mathrm{x})$; bare land habitats: $\mathrm{y} 11=$ $\exp (-1.30+0.15 \mathrm{x})$. Statistics for the minimal adequate model are $\mathrm{F}=187.777 ; \mathrm{df}=13,873 ; \mathrm{P}<0.001 ; \mathrm{r}_{\mathrm{L}}^{2}=0.751$. (Some observed data on herptiles, birds, insects, mammals and plants are slightly shifted to make all points visible). The model has a similar structure as the linear model in the main text. The most important difference is that this model predicts higher numbers of alien plant species, but their less rapid increase with increasing habitat area than the linear model. However, as in the linear model in Fig. 2, the rate of increase across habitats of insects and plants differs from vertebrate groups (deletion test on the same rate of increase for all taxonomic groups: $\mathrm{F}=24.11$; $\mathrm{df}=4,868$; 
$\mathrm{P}<0.001$ ) and is the same across taxa in all habitats (deletion test on different rate of increase in individual habitats: $\mathrm{F}=0.44$; $\mathrm{df}=9,859$; NS), although the habitats differ in the number of alien species (deletion test on the same number of species in all habitats: $\mathrm{F}=43.76$; $\mathrm{df}=8,875 ; \mathrm{P}<0.001)$. 